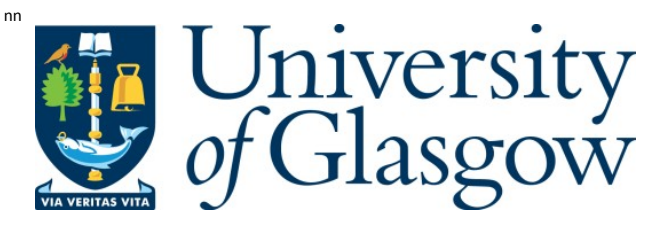

Ramesh, K., Edwards, J. R., Chelliah, H., Goyne, C., M cDaniel, J., Rockwell, R., K irik, J., Cutler, A ., and Danehy, P. (2015) Large Eddy Simulation of High-Speed, Premixed Ethylene Combustion. In: 53rd A IA A A erospace Sciences M eeting, K issimmee, FL, USA , 5-9 J an 2015

Copyright @ 2015 Jack R. Edwards

A copy can be downloaded for personal non-commercial research or study, without prior permission or charge

Content must not be changed in any way or reproduced in any format or medium without the formal permission of the copyright holder(s)

http://eprints.gla.ac.uk/103543/

Deposited on: 27 February 2015

Enlighten - Research publications by members of the University of Glasgow http://eprints.gla.ac.uk 


\title{
Large Eddy Simulation of High-Speed, Premixed Ethylene Combustion
}

\author{
Kiran Ramesh ${ }^{1}$ and Jack R. Edwards ${ }^{2}$ \\ North Carolina State University, Raleigh, North Carolina \\ Harsha Chelliah ${ }^{3}$, Christopher Goyne ${ }^{4}$, James McDaniel ${ }^{5}$, Robert Rockwell ${ }^{6}, \mathrm{Justin}_{\text {Kirik }}{ }^{7}$ \\ University of Virginia, Charlottesville, Virginia \\ Andrew Cutler ${ }^{8}$ \\ The George Washington University, Hampton, Va \\ Paul Danehy ${ }^{9}$ \\ NASA Langley Research Center, Hampton, Va
}

\begin{abstract}
A large-eddy simulation / Reynolds-averaged Navier-Stokes (LES/RANS) methodology is used to simulate premixed ethylene-air combustion in a model scramjet designed for dual mode operation and equipped with a cavity for flameholding. A 22-species reduced mechanism for ethylene-air combustion is employed, and the calculations are performed on a mesh containing 93 million cells. Fuel plumes injected at the isolator entrance are processed by the isolator shock train, yielding a premixed fuel-air mixture at an equivalence ratio of 0.42 at the cavity entrance plane. A premixed flame is anchored within the cavity and propagates toward the opposite wall. Near complete combustion of ethylene is obtained. The combustor is highly dynamic, exhibiting a large-scale oscillation in global heat release and mass flow rate with a period of about $2.8 \mathrm{~ms}$. Maximum heat release occurs when the flame front reaches its most downstream extent, as the flame surface area is larger. Minimum heat release is associated with flame propagation toward the cavity and occurs through a reduction in core flow velocity that is correlated with an upstream movement of the shock train. Reasonable agreement between simulation results and available wall pressure, particle image velocimetry, and OH-PLIF data is obtained, but it is not yet clear whether the system-level oscillations seen in the calculations are actually present in the experiment.
\end{abstract}

\section{Introduction}

The need to rapidly mix fuel and air in sufficient proportions to enable combustion is a pacing issue in the design of dual-mode scramjet engines designed for high Mach number operation. If fuel and air can be premixed prior to entering the combustor and if a premixed flame can be successfully stabilized through some means, then the combustor length required can be reduced to its minimum possible extent, which is associated with the average flame propagation angle. The flame propagation angle itself is a function of the fuel type, the local equivalence ratio, the mean velocity of the incoming flow upstream of the flame, the temperature of the reactants, and the

\footnotetext{
${ }^{1}$ Research Associate, Department of Mechanical and Aerospace Engineering, Member, AIAA.

${ }^{2}$ Professor, Department of Mechanical and Aerospace Engineering, Associate Fellow, AIAA.

${ }^{3}$ Professor, Department of Mechanical and Aerospace Engineering, Associate Fellow, AIAA.

${ }^{4}$ Associate Professor, Department of Mechanical and Aerospace Engineering, Associate Fellow, AIAA.

${ }^{5}$ Professor, Department of Mechanical and Aerospace Engineering, Associate Fellow, AIAA.

${ }^{6}$ Senior Research Scientist, Department of Mechanical and Aerospace Engineering, Senior Member, AIAA.

${ }^{7}$ Graduate Research Assistant, Department of Mechanical and Aerospace Engineering, Student Member, AIAA.

${ }^{8}$ Professor, Department of Mechanical and Aerospace Engineering, Associate Fellowr, AIAA.

${ }^{9}$ Physicist, Advanced Sensing and Optical Measurement Branch, Associate Fellow, AIAA.
} 
turbulence intensity of the incoming flow. The last two years of the AFOSR/NASA National Center for CombinedCycle Hypersonic Propulsion have focused on examining the situation described above and have been designed to answer the following questions:

1. Is possible to uniformly premix fuel and air so that the ideal combustor inflow state is realized at an equivalence ratio sufficiently large to sustain combustion?

2. Is it possible to stabilize a premixed flame in a cavity and to observe its propagation across the extent of the combustor?

3. Can the characteristics of this flame be described in terms of classical premixed-flame theory, keeping in mind that the environment is extreme, with turbulence intensities upwards of $20 \%$ and inflow Mach numbers greater than 0.5 ?

This paper reports on the computational portions of the combined experimental / computational effort focusing on these issues. The initial thrust of the effort, described in brief in this paper and conducted through a large number of Reynolds-averaged Navier-Stokes (RANS) simulations, was to determine whether or not complete pre-mixing was possible, given facility constraints that limit the allowable equivalence ratio. The majority of the paper describes the use of hybrid large-eddy simulation / Reynolds-averaged Navier-Stokes (LES/RANS) techniques to simulate premixed flame propagation in the experimental apparatus, located at the University of Virginia's Scramjet Combustion Facility. The LES/RANS methodology has been tested for hydrogen-air nonpremixed combustion $[1,2]$ using nine-species reaction models and for ethylene-air partially-premixed combustion [3] using a 22-species reduced chemical kinetics model. The simulations described herein are distinct from our previous works in that the combustor operates in dual mode, with a tight coupling between isolator shock-train motion and combustion-induced heat release driving the flow response.

\section{LES/RANS Models and Numerical Methods}

\section{A. LES/RANS model}

The LES/RANS model considered in this work [4] uses the Menter BSL (baseline) model [5] as its basis, and the modification only involves the alteration of the eddy viscosity field according to the following prescription:

$$
v_{\mathrm{t}}=\Gamma v_{t, \text { RANS }}+(1-\Gamma) v_{t, L E S}
$$

where $v_{t, \text { RANS }}=k / \omega$ is obtained from the Menter BSL model, and the subgrid eddy viscosity is the mixed-scale model of Lenormand, et al. [6]. A flow-dependent blending function developed by Gieseking et al [4] is used to shift the model from unsteady RANS near the walls to LES in the freestream:

$$
\begin{gathered}
\Gamma=\frac{1}{2}\left(1+\tanh \left[C_{s}\left(\frac{1}{\lambda_{N}^{2}}-1\right)\right]\right\}, \quad C_{s}=15 \\
\lambda_{N} \equiv \frac{l_{\text {outer }}}{l_{\text {inner }}}, \quad l_{\text {outer }}=C_{N} \sqrt{\frac{10 v \bar{\omega}+\bar{k}+\bar{k}_{R}}{c_{\mu}^{\frac{1}{2}} \bar{\omega} \omega}}, \quad C_{N}=1.5, \quad l_{\text {imer }}=\kappa d
\end{gathered}
$$

The blending function attempts to create the LES/RANS transition near the point where the logarithmic region of the boundary layer transitions to wake-like behavior, with the factor $\lambda_{N}$ representing the ratio of the outer and inner layer turbulence length scales. In the expression, $d$ is the wall distance, $\kappa=0.41$ is the Von Karman constant, and $C_{\mu}=0.09$. In order to make the blending less sensitive to the initial distribution of the modeled turbulent kinetic energy, the ensemble-averaged resolved TKE is used to augment the modeled turbulent kinetic energy in Eq. (3). 


$$
\bar{\rho} \bar{k}_{R}=\frac{1}{2}\left(\overline{\rho u_{k} u_{k}}\right)-\frac{\overline{\rho u_{k}} \overline{\rho u_{k}}}{\bar{\rho}}
$$

The overbars in Eq. (3) represent ensemble-averaged quantities, which are computing using a weighted ensembleaveraging method over a period equal to four combustor transit times. The use of ensemble-averaging leads to a smoother behavior of the blending function.

Salazar and Edwards [7] introduced a grid correction function in the definition of the length scale ratio so as to take grid resolution into consideration while determining the RANS to LES transition. With Salazar's fix, the length scale ratio is redefined as

$$
\lambda_{N} \equiv \frac{l_{\text {outer }} g\left(l_{\text {outer }}\right)}{l_{\text {inner }}}, \quad g\left(l_{\text {outer }}\right)=\min \left[10, \max \left(1, \frac{1}{2} \frac{\Delta_{\text {max }}}{l_{\text {outer }}}\right)\right]
$$

The inclusion of grid spacing $\Delta_{\max }=\max (\Delta x, \Delta y, \Delta z)$ in determining the eddy viscosity blending function facilitates a different transition between LES and RANS by avoiding the implementation of LES in those regions where the grid is too coarse to support LES. This approach was used exclusively in this work.

\section{B. Combustion model}

The simulations considered herein utilize the Taitech-Princeton-2 (TP-2) [8] 22-species reduced mechanism for combustion of methane / ethylene mixtures. Chemical source terms provided by TP-2 are a result of sequences of operations involving hard-coded (Fortran) elementary reaction rates. Numerical precision losses may result in non-zero sums of the chemical source terms (of the order of $10^{-5}$ ) To ensure that the source terms exactly sum to zero, they are modified as follows:

$$
\dot{\omega}_{s}=\dot{\omega}_{s, T P-2}-Y_{s} \sum_{k} \dot{\omega}_{k, T P-2}
$$

The chemical source terms are evaluated using filtered mean data (the 'laminar chemistry') assumption. Species diffusivity and heat condition are modeled using Fick's law and Fourier's law, respectively. Constant laminar and turbulent Schmidt numbers (0.5) and Prandtl (0.7 and 0.9) numbers are used to connect the diffusion coefficient and thermal conductivity to the mixture viscosity (obtained from Wilke's law) and the mixture specific heat.

\section{Numerical methods}

A finite-volume formulation of the compressible Navier-Stokes equations is utilized, and a second-order Crank-Nicholson scheme, implemented using an implicit dual time-stepping strategy, is employed for time advancement. For the inviscid fluxes, Edwards' low diffusion flux splitting scheme (LDFSS) [9], extended to higher-order spatial accuracy using the Piecewise Parabolic Method (PPM) [10] scheme applied to the primitive variables $W=\left[p_{s}, u, v, w, T, k, \omega\right]^{T}$, is used. It is necessary to reduce the numerical dissipation significantly in regions of high turbulence activity. This is accomplished by blending left- and right states determined from PPM (superscript ' $\mathrm{M}$ ' in Eq. 7) with an averaging operator that yields a fourth-order central difference on uniform meshes (Eq. 8). At cell interface $i+1 / 2$, the modified reconstruction is

$$
\begin{aligned}
& V_{L, i+1 / 2}=V_{L, i+1 / 2}^{A}+\max \left(f_{i}, f_{i+1}\right)\left(V_{L, i+1 / 2}^{M}-V_{L, i+1 / 2}^{A}\right) \\
& V_{R, i+1 / 2}=V_{R, i+1 / 2}^{A}+\max \left(f_{i}, f_{i+1}\right)\left(V_{R, i+1 / 2}^{M}-V_{R, i+1 / 2}^{A}\right)
\end{aligned}
$$

with

$$
V_{L, i+1 / 2}^{A}=V_{R, i+1 / 2}^{A}=\frac{7}{12}\left(V_{i}+V_{i+1}\right)-\frac{1}{12}\left(V_{i+2}-V_{i-1}\right)
$$

The blending function is the vorticity / divergence function of Ducros, et al. [11]

$$
f=\frac{(\nabla \cdot \vec{V})^{2}}{(\nabla \cdot \vec{V})^{2}+|\omega|^{2}+\varepsilon^{2}}, \quad \varepsilon=1 \times 10^{-8} V_{\infty} / \max (\overline{\Delta x}, \overline{\Delta y}, \overline{\Delta z})
$$


where $\overline{\Delta x}, \overline{\Delta y}$ and $\overline{\Delta z}$ are the average mesh spacings in the three Cartesian coordinate directions. Here, the divergence of velocity is compared with the vorticity value. If the latter is much larger (in shear and boundary layers, for example), the function moves toward zero, and in free-stream regions near shocks, the function approaches one. Viscous fluxes are discretized using central differences.

\section{Simulation Details}

A side view of the geometry considered is shown in Figure 1. The geometry consists of three major components: an isolator, a combustor section with a cavity for flameholding, a straight section, and an extender. The flow exits to ambient conditions at the end of the extender. The experimental configuration contains 68 fuel injectors, with 24 located in four banks of three injectors on the top (cavity side) and bottom (opposite the cavity) walls at the beginning of the isolator, 24 arranged in a similar configuration midway within the isolator, 15 located in three banks of five injectors upstream of the cavity on the top wall, and 5 more located on the back face of the cavity. In this study, the injectors located midway along the isolator and just upstream or within the cavity were not used, and only four of the eight banks located at the beginning of the isolator were employed. Several tradeoff studies were conducted using NO-PLIF diagnostics and RANS CFD to determine the injection pattern that led to the most uniform premixed state of fuel and air just upstream of the cavity entrance plane. The optimal mixing pattern was found by injecting normal to the flow through the four most downsream banks at the beginning of the isolator.

The converging / diverging nozzle that leads to the isolator / combustor geometry is not shown in the schematic. An inflow plane generated from a previous simulation of the nozzle flow that accounts for a persistent non-uniformity in the stagnation temperature was used for these simulations. [1] The nominal stagnation conditions for the air stream are $300 \mathrm{kPa}$ and $1200 \mathrm{~K}$. No-slip, isothermal wall boundary conditions $\left(\mathrm{T}_{\text {wall }}=600 \mathrm{~K}\right)$ were employed on all solid surfaces. The wall temperature value is an average of reported thermocouple results [12]. Due to a multiplicity of materials, coolant passages, and barrier coatings used in the rig, the actual wall temperature distribution is very difficult to determine. The sensitivity to the calculations to the wall temperature remains to be addressed. Supersonic inflow boundary conditions were imposed at the entrance to the isolator. Sonic inflow conditions corresponding to a global equivalence ratio (ER) of 0.42 (distributed over the active fuel ports and assuming a $300 \mathrm{~K}$ fuel reservoir temperature) were imposed at the entrances of the small straight tubes shown in Figure 1. In the computational domain, the extender connects to a dump region that allows the exiting plume to adjust to the ambient conditions more gradually. Ambient pressure levels are imposed at the outer boundaries of the dump region.

The computational model of the domain consists of 93 million grid cells subdivided into 13369 blocks. The mesh was generated using GridPro (Program Development Company) and was designed to maintain a nominal isotropic mesh spacing of about $0.25 \mathrm{~mm}$ in the interior of the geometry. The mesh spacing on all solid surfaces is 5 $\mu \mathrm{m}$. The mesh expands rapidly in the dump region, leading to very high aspect ratio cells. In this region, the discretization was forced to revert to PPM (without the Ducros blending function) to avoid numerical problems. The LES/RANS simulations were evolved at a constant time step of $0.2 \mu \mathrm{s}$.

\section{Results}

\section{A. RANS mixing studies}

As mentioned earlier, many tradeoff studies using RANS simulations were performed to determine the fuel injection configuration that led to the highest degree of fuel uniformity at the cavity entrance plane and within the cavity. The overall equivalence ratio was constrained in the experiment to be no greater than 0.45 , as higher values resulted in flame propagation up to the fuel injectors. With this constraint, it was noticed that complete pre-mixing could only be obtained if a shock train were present in the isolator (dual-mode operation). Figure 2 shows ER distributions and longitudinal variability in ER from two different fueling configurations: 0.27 (top), 0.15 (bottom) and 0.21 (top), 0.21 (bottom). In these cases, an air throttle was used to position the leading edge of the shock train just downstream of the fuel injector banks. Better flow uniformity results from equal fuel splits between the upper 
and lower injection banks, but a perfectly-mixed state is not realized due to non-uniformities in the incoming air stream and to the three-dimensional shock-train structure. Nevertheless, large regions of fuel-air stratification are not observed, as verified by NO-PLIF (see separate paper in this session), indicating that shock-train induced mixing enhancement is a viable means of producing a well-mixed combustor entrance state.

\section{B. LES/RANS Combusting Studies}

Following the mixing-only RANS studies, reactive calculations were initiated, again using RANS, with the air throttle in place. These were used to initialize the LES/RANS calculations. After evolving the flow several combustor transit times to complete the transition to LES/RANS and after removing the air throttle, a cyclic pattern of combustor operation began to emerge, as illustrated in Figure 3, which shows volumetric heat release and inflow / outflow mass flow rates versus time. The volumetric heating measure includes the dump region and thereby overestimates the actual heat release within the combustor. Large heat release is associated with exiting mass flow rates higher than incoming and, as shown later, with higher core flow velocities upstream of the combustor. Reduced levels of heat release are associated with exiting mass flow rates lower than incoming, meaning that mass accumulates in the combustor before being expelled.

It is useful to examine the flame structure at time instances corresponding to maximum heat release and minimum heat release and to compare with the time average extracted over all periods. Figures 4-6 show several such comparisons, extracted along the combustor midplane $(\mathrm{Z}=0)$ and extending from just upstream of the cavity to the extender exit plane. Ethylene mass fraction contours in Figure 4 clearly show the propagation of a cavitystabilized premixed flame across the combustor duct. Near complete combustion of ethylene occurs, and the premixed flame front is shown to be captured sharply in the instantaneous images. Flame wrinkling due to local turbulence is evident as is an increase in the flame surface area at the maximum heat release point (bottom). The flame front moves toward the cavity and its angle steepens at the minimum heat release point. The flame surface area diminishes at this point due to its quenching as it encounters the cold opposite-wall boundary layer. The effective flame front in the time average is much broader, as the averaging process filters out turbulence-induced wrinkles in the flame front as well as cyclic variations in the flame angle. It is of note that the local fuel mass fraction upstream of the flame front is higher when the combustor is at a maximum heat release position. This indicates that the mixing process is being affected by the shock train dynamics.

Similar trends are noted in the temperature distributions shown in Figure 5. Burned gas temperatures range near $2000 \mathrm{~K}$. Temperatures within the cavity range from about 1600 degrees near the upstream end to 2100 degrees near the downstream end. Again, the 'flame brush' effect is evident in the time-averaged solution. The flame angle is nearly straight until the flame encounters the cooler opposite-wall boundary layer and ceases to propagate. Thermal choking occurs at the end of the straight section. The flow then expands to low supersonic speeds before re-compressing through a normal shock wave in the extender.

Axial velocity contours in Figure 6 show that downstream propagation of the flame front is associated, as expected, with higher average core velocities. Low momentum regions located upstream of the cavity, along with a lower core flow velocity, enable the upstream propagation of the flame at the minimum heat-release points in the cycle. The average velocity upstream of the cavity is around $350 \mathrm{~m} / \mathrm{s}$, whereas the average $r m s$ velocity (not shown) is around $50 \mathrm{~m} / \mathrm{s}$. Figure 7 shows a comparison of centerplane axial velocity with a limited set of PIV data in the vicinity of the cavity shear layer. Velocity magnitudes are in relatively close agreement, but the predicted shear layer extends straight across the cavity, whereas the experimental data indicates that the shear layer deflects into the cavity. This may indicate a higher level of volumetric expansion of cavity fluid in the calculation versus the experiment and by inference, a higher average level of heat release.

In addition to PIV, experimental data for this configuration includes OH-PLIF imagery and CARS. A qualitative comparison between OH-PLIF intensity and computed $\mathrm{OH}$ mass fraction is shown in Figure 8. Good agreement in the sizes of eddies and the overall extent of flame propagation is observed at this instance in time. Also noted is a region of diminished $\mathrm{OH}$ production at the leading edge of the cavity seen in both the computational snapshot and the image. Concentrations of major combustion products are very high in the region though temperatures are relatively low, implying that this portion of the cavity is filled by hot, burned gases that are 
forced toward the front of the cavity by the recirculation process. These gases provide an ignition source for the fresh fuel-air mixture as it is entrained into the cavity shear layer. Processed CARS measurements of major species and temperature were not available for comparison at the time of this writing. Raw CARS data has been collected in the planes shown in Figure 9. The computational predictions indicate that the flow inside the cavity is nominally two-dimensional. Away from the cavity, the premixed flame front is very thin and is strongly wrinkled by largescale turbulence. The flame becomes more three-dimensional further downstream, with the time-averaged results indicating increased reactivity toward the centerline and near the walls along with a pronounced asymmetry. The 'flame brush' effect on the averaged temperature and $\mathrm{CH}_{2} \mathrm{O}$ fields is particularly prominent.

Centerplane flame-angle predictions are compared with contours of time-averaged temperature, $\mathrm{OH}$ mass fraction and the product of $\mathrm{OH}$ and $\mathrm{CH}_{2} \mathrm{O}$ mass fractions in Figure 10. The latter is an approximate measure of the heat-release region. The turbulent flame speed is estimated by Zimont's formula [13], given by Eq. 11.

$$
\begin{aligned}
& \frac{S_{T}}{S_{L}}=0.52\left(0.71 \operatorname{Re}_{\lambda}\right)^{1 / 4}\left(u^{\prime} / S_{L}\right)^{1 / 2}, \\
& \operatorname{Re}_{\lambda}=\frac{\rho u^{\prime} \lambda}{\mu}
\end{aligned}
$$

The laminar flame speed is obtained from a correlation due to Brown and Lawn [14], which is valid for equivalence ratios between 0.35 and 1.0 and reactant temperatures between 200 and $1100 \mathrm{~K}$. The rms axial velocity is obtained from ensemble-averaging the LES data, while the integral length-scale estimate $(\lambda=5 \mathrm{~mm}$ ) is obtained from an auto-correlation analysis of the centerline velocity field. The predicted flame front is assumed to originate at the cavity leading edge; it is clear from $\mathrm{OH}$ mass-fraction and the product of $\mathrm{OH}$ and $\mathrm{CH}_{2} \mathrm{O}$ mass fractions that the actual flame inception location is nearer to the trailing edge of the cavity. The predicted flame angle itself is in good agreement with the computational data.

The average pressure distribution along the upper (cavity-side) wall is shown in Figure 11. The 'error bars' show one standard deviation in the pressure signal, giving a further indication of the level of large-scale unsteadiness present in the computation. Good agreement with the experimental distribution (obtained through conventional pressure taps) is indicated, though the upstream extent of the predicted shock train extends more toward the fuel injectors. This again indicates a possible over-prediction of heat release. Upper-wall pressure distributions conditionally averaged near local maxima $(|q|>400000)$ and local minima $(|q|<230000)$ in the heat release time history are shown in Figure 12. These, along with associated animations, indicate that minimum heat release is associated with a pressure maximum near the cavity and the propagation of a normal shock wave toward the isolator entrance. This shock wave reduces the core flow velocity significantly, leading to the response shown in Figure 5. The shock strength diminishes as it nears the isolator entrance plane, allowing the core flow to accelerate. This forces the flame front downstream and enables more contact of the fuel-air mixture with the flame front, thus increasing heat release. The conditionally-averaged pressure distribution near the cavity trends below the experimental values at maximum heat-release. A concern revealed by the animations is that the amplitude of the large-scale pressure oscillations in the isolator increases with time, with the leading edge of the shock train reaching the injectors at the last computed cycle. A global Rayleigh criterion [15] can be used to measure whether or not combustion instability might be present. This is computed as

$$
\begin{aligned}
& R=\frac{1}{T} \int_{T} p^{\prime}(t) q^{\prime}(t) d t, \\
& p^{\prime}(t)=\frac{1}{L} \int_{L}(p(x, t)-\overline{p(x)}) d x / \frac{1}{L} \int_{L} \overline{p(x)} d x, \\
& q^{\prime}(t)=(q(t)-\bar{q}) / \bar{q}
\end{aligned}
$$

where the overbar designates a time average over the entire simulation, $T$ represents one period of oscillation, and $L$ is the length of the domain. The global Rayleigh criterion is negative for all periods tested, indicating that the system should be thermo-acoustically stable. Nevertheless, an increase in amplitude of pressure and heating rate fluctuations is observed, as shown in Figure 13, over the duration of the simulation. 
The ability of a cavity to provide adequate flameholding for premixed combustion is related to the residence time available for reactions to take place, the average velocity and turbulence intensity within the cavity and the local equivalence ratio distribution prior to contact of the fresh fuel-air mixture with the flame front. Figure 14 shows residence time distributions computed from an ensemble of streamlines entering and leaving the cavity. One distribution corresponds to an instantaneous solution extracted near a local maximum in the heat release distribution, while the other corresponds to the time average over all computed cycles of combustor operation. It is clear that the most probable residence time extracted from the time average $(\sim 11 \mathrm{~ms})$ is significantly higher than that from the instantaneous snapshot ( 2.5 ms). Velocity distributions in Figure 15 show that this response is consistent with a marked reduction in the time-averaged cavity velocity relative to the instantaneous velocity. An earlier mapping of residence times (based on time-averaged data) for a similar combustor operating under scram-mode conditions [3] yielded a most probable residence time of about $2.8 \mathrm{~ms}$ - significantly shorter than that obtained under the present dual-mode conditions. This result explains the relative ease in which the lean premixed flame is stabilized within the cavity in the dual-mode environment, as typical induction times for ethylene-air ignition at ER $=0.42$ are of the order of $2 \mathrm{~ms}$. These results also indicate that the average cavity turnover time may not be the driving factor in determining the global oscillation period $(2.8 \mathrm{~ms})$, but further examinations of the instantaneous residence-time distributions at other points in the cycle are needed.

\section{Conclusions}

Simulations of cavity-stabilized premixed flame propagation in a dual-mode scramjet combustor have been performed using a large-eddy simulation / Reynolds-averaged Navier-Stokes (LES/RANS) turbulence closure along with a 22-species ethylene oxidation model. Establishment of dual-mode (i.e. thermal-throat ramjet) combustor operation is essential for ensuring nearly uniform pre-mixing of fuel and air upstream of the cavity. Mixing enhancement is facilitated by interactions of the jet plumes with the isolator shock train, leading to near complete homogenization of the fuel-air mixture at the end of the isolator. LES/RANS simulations show that the combustor response is characterized by an oscillation in heat release and average combustor pressure level with a period of about $2.8 \mathrm{~ms}(357 \mathrm{~Hz})$. The flame angle varies significantly over the cycle, with maximal heat release corresponding to a shallower flame angle with increased flame surface area and to higher core flow velocities. Minimal heat release corresponds to a steeper flame angle, decreased flame surface area, and lower core flow velocities. The reduction in core-flow velocity at minimal heat release is a consequence of the upstream propagation of a normal shock wave within the isolator. This shock wave decreases in strength as it nears the fuel injectors, enabling an increase in core flow velocity that continues the cycle. The cyclic operation of the combustor appears to be thermo-acoustically stable according to a global Rayleigh criterion. Nevertheless, the amplitudes of average pressure and heat release do increase, with the shock train reaching the fuel injectors at the last period of oscillation.

Flame-angle predictions using Zimont's estimate of the turbulent flame speed are in good agreement with computational time-averaged images. The flame itself is stabilized at a position about two-thirds along the cavity length, near the point where the ramp begins to close the cavity. The region upstream of the stabilization location is associated with high concentrations of major product species and lower temperatures; this region acts as an ignition source for freshly-entrained premixed fluid. Cavity residence-time estimates indicate significant differences between the instantaneous flow response and the time-mean response, with the latter implying a most-probable cavity residence time of over $10 \mathrm{~ms}$. This rather large value shows why dual-mode operation is favorable for flame stabilization.

Comparisons with experimental wall pressure, OH-PLIF imagery, and PIV are generally favorable, though indications of an over-prediction of heat release in the simulations are present. It is unclear whether the actual experiment shows the cyclic behavior revealed in the calculations, and the causes of the observed characteristic frequency of $357 \mathrm{~Hz}$ remain to be established. 


\section{Acknowledgements}

This work was supported by the National Center for Hypersonic Combined Cycle Propulsion under AFOSR grant FA 9550-09-1-0611, monitored by Dr. Chiping Li. Computer resources were provided by the NASA Advanced Supercomputing (NAS) division and the DoD High Performance Computing Modernization Program.

\section{References}

[1] Fulton, J.A., Edwards, J.R., Hassan, H.A. , McDaniel, J.C., Goyne, C.P., Rockwell, R.D, Cutler, A.D., Johansen, C.T., and Danehy, P.M. "Large-Eddy / Reynolds-Averaged Navier-Stokes Simulations of Reactive Flow in a Dual-Mode Scramjet Combustor", Journal of Propulsion and Power, Vol. 30, 2014, pp. 558-575.

[2] Fulton, J.A., Edwards, J.R., Cutler, A.D., McDaniel, J.C., Goyne, C.P. "Turbulence / Chemistry Interactions in a Ramp-Stabilized Supersonic Hydrogen-Air Diffusion Flame" AIAA 2014-0627, 52 ${ }^{\text {nd }}$ Aerospace Sciences Meeting, 2014.

[3] Potturi, A.S. and Edwards, J.R. 'Large-Eddy / Reynolds-Averaged Navier-Stokes Simulation of CavityStabilized Ethylene Combustion" in press, Combustion and Flame.

[4] Gieseking, D.A., Choi, J.-I., Edwards, J.R., and Hassan, H.A. "Compressible Flow Simulations using a New LES/RANS Model” AIAA Journal, Vol. 49, No. 10, 2011, pp. 2194-2209.

[5] Menter, F. R., "Two-Equation Eddy-Viscosity Turbulence Models for Engineering Applications", AIAA Journal, Vol. 32, No. 8, August 1994, pp, 1598-1605.

[6] Lenormand, E., Sagaut, P., Ta Phuoc, L, and Comte, P. "Subgrid-Scale Models for Large-Eddy Simulations of Compressible, Wall-Bounded Flows,” AIAA Journal, Vol. 38, 2000, pp. 1340-1350.

[7] Salazar, G.. and Edwards, J.R. "Mach 6 Wake Flow Simulations using a Large-Eddy Simulation / Reynolds-Averaged Navier-Stokes Model", Journal of Spacecraft and Rockets, Vol. 51, pp. 1329-1348, 2014.

[8] Luo, Z., Yoo, C.S., Richardson, E.S., Chen, J.H., Law, C.K., and Lu, T. "Chemical Explosive Mode Analysis for a Turbulent Lifted Ethylene Jet Flame in Highly-Heated Coflow", Combustion and Flame, Vol. 159, No. 1, 2012, pp. 265-274

[9] Edwards, J.R. "A Low-Diffusion Flux-Splitting Scheme for Navier-Stokes Calculations," Computers and Fluids, Vol. 26, No. 6, 1997, pp. 635-659.

[10] Colella, P. and Woodward, P.R. "Piecewise Parabolic Method for Gas-Dynamical Simulations," Journal of Computational Physics, Vol. 5, No. 1, 1984, pp. 174-201.

[11] Ducros, F., Ferrand, V., Nicaud, F., Weber, C., Darracq, D., Gachareiu, C., Poinsot, T. "Large-Eddy Simulation of the Shock / Turbulence Interaction" Journal of Computational Physics, Vol. 152, No. 2., 1999, pp. 517-549.

[12] Rockwell, R.D., Goyne, C.P., Rice, B.E., Tatman, B.J., Smith, C., Kouchi, T., McDaniel, J.C., Fulton, J.A., and Edwards, J.R. "Collaborative Experimental and Computational Study of a Dual Mode Scramjet Combustor", Journal of Propulsion and Power, Vol. 30, 2014, pp. 530-538

[13]Zimont, V.L. "Gas Premixed Combustion at High Turbulence. Turbulent Flame Closure Model Combustion Model" Experimental Thermal and Fluid Science, Vol. 21, 2000, pp. 179-186.

[14]Brown, M.J. and Lawn, C.J., in: ECM 2003, Proceedings of the $1^{\text {st }}$ European Combustion Meeting, Orleans, France, pp. 1-5.

[15] Menon, S. and Jou, W.-H. "Large Eddy Simulation of Combustion Instability in an Axisymmetric Ramjet Combustor" Combustion Science and Technology, Vol. 75, No. 1, 1991, pp. 53-72. 

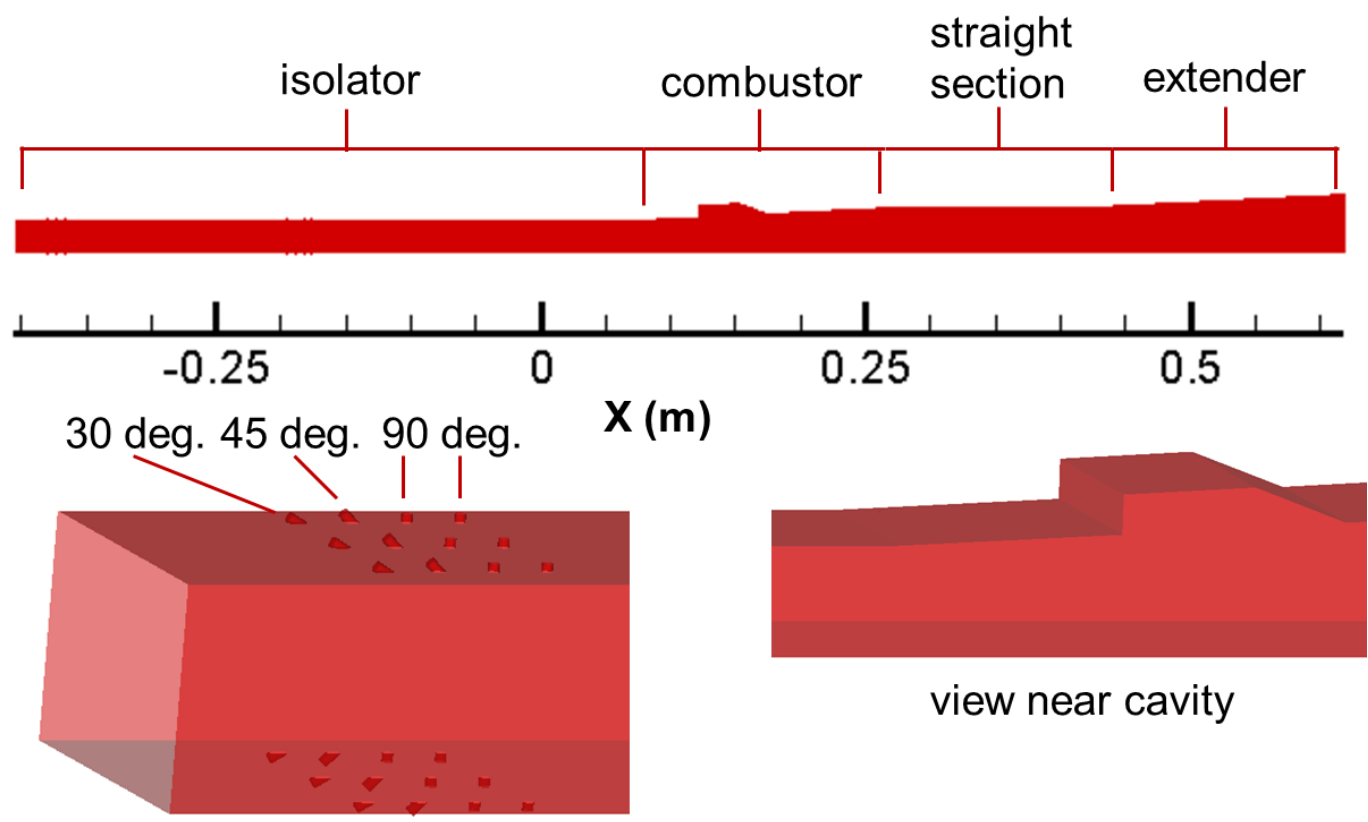

view near cavity

Figure 1: Schematic of combustor rig with closeup view of fuel injectors and cavity
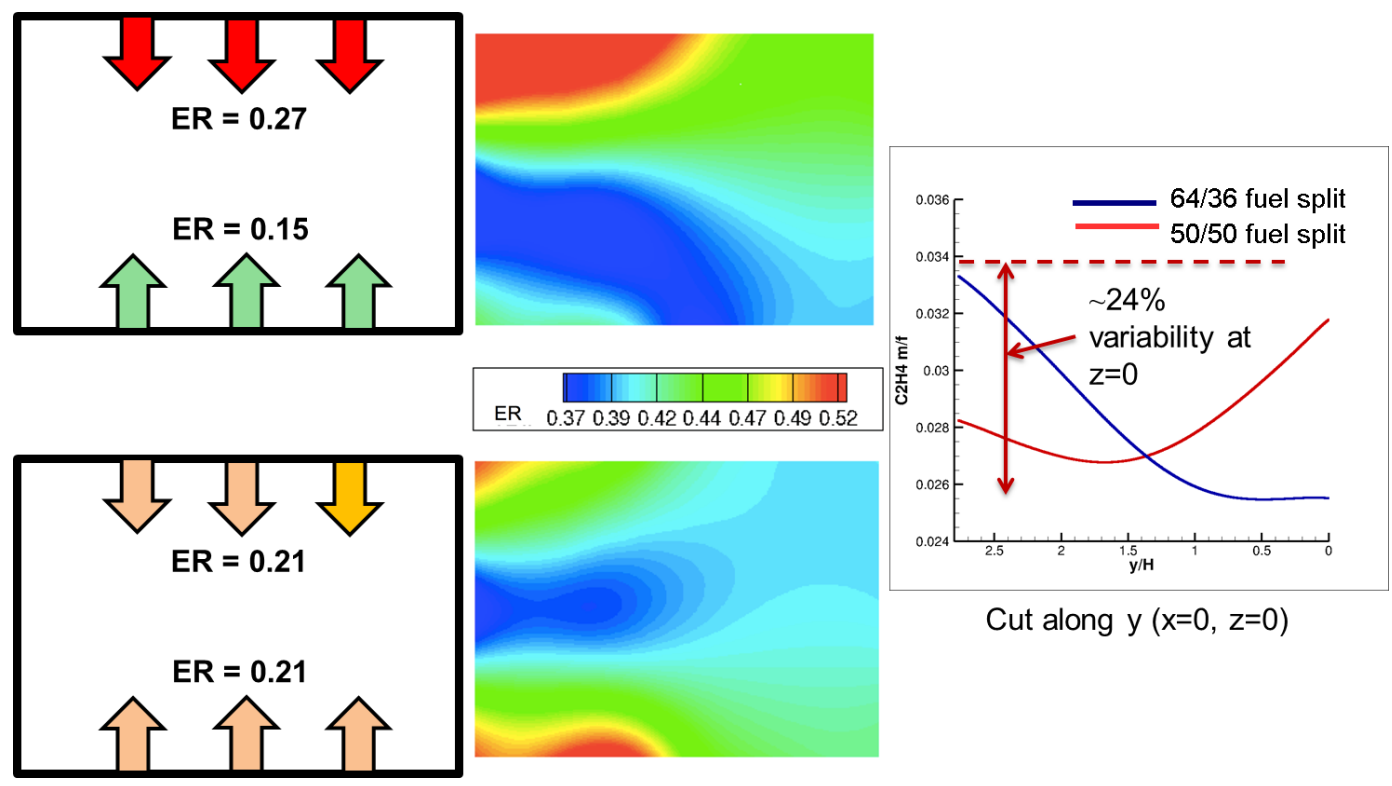

Cut along y $(x=0, z=0)$

Figure 2: Cavity entrance plane ER distributions and uniformity measures 


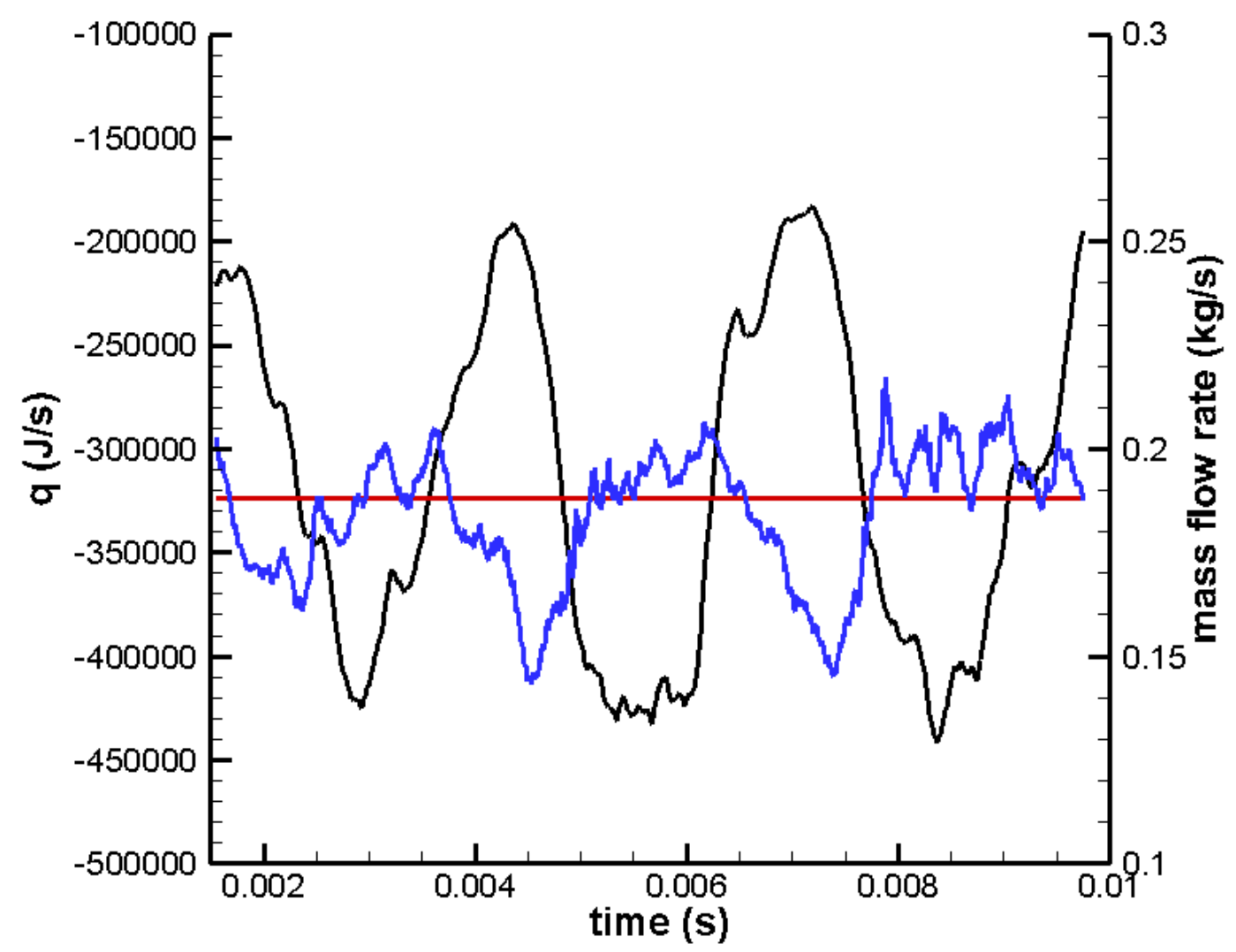

Figure 3: Heating rate and mass flow rates

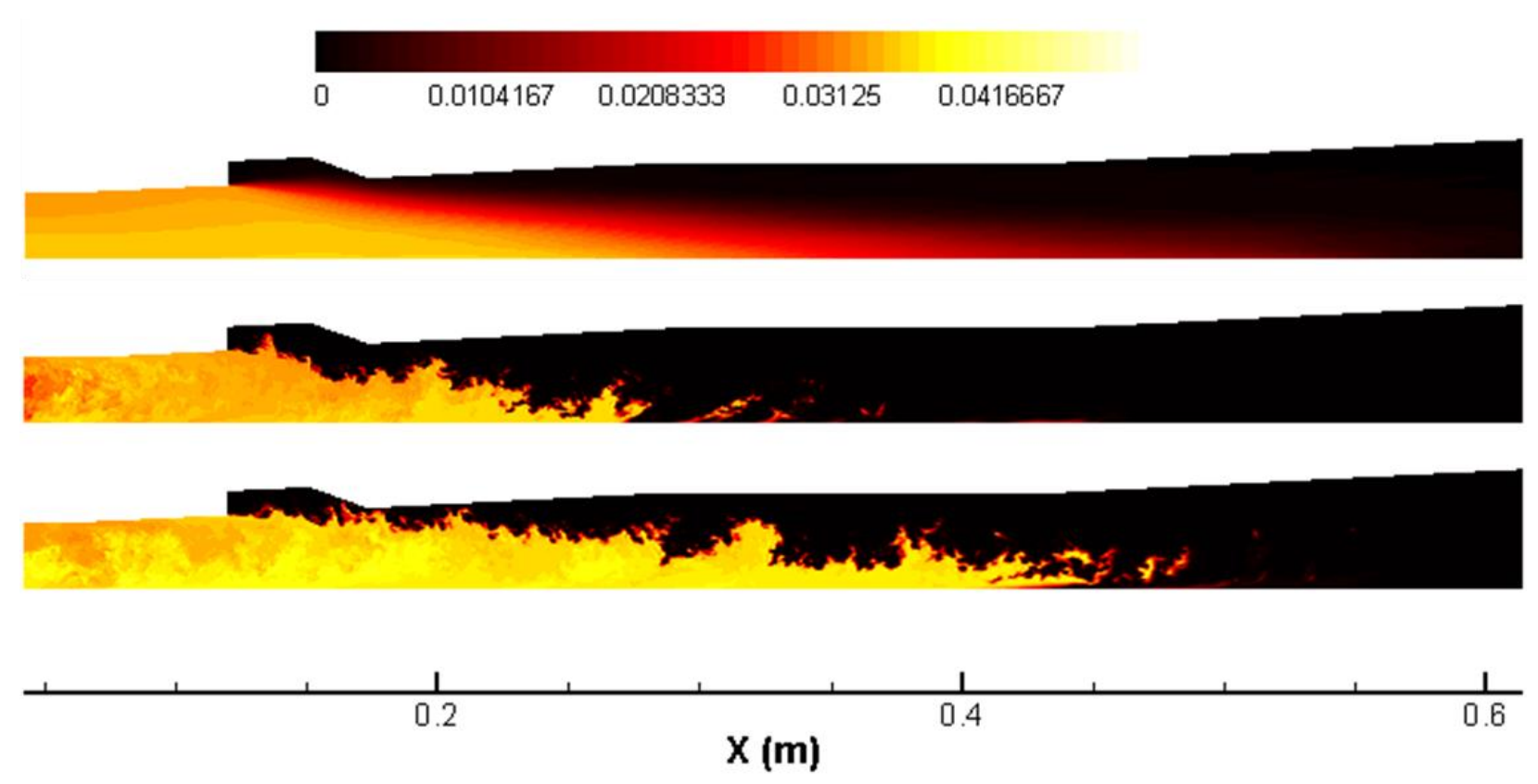

Figure 4: Ethylene mass fraction contours (top: average; middle: minimum heat release; bottom: maximum heat release) 

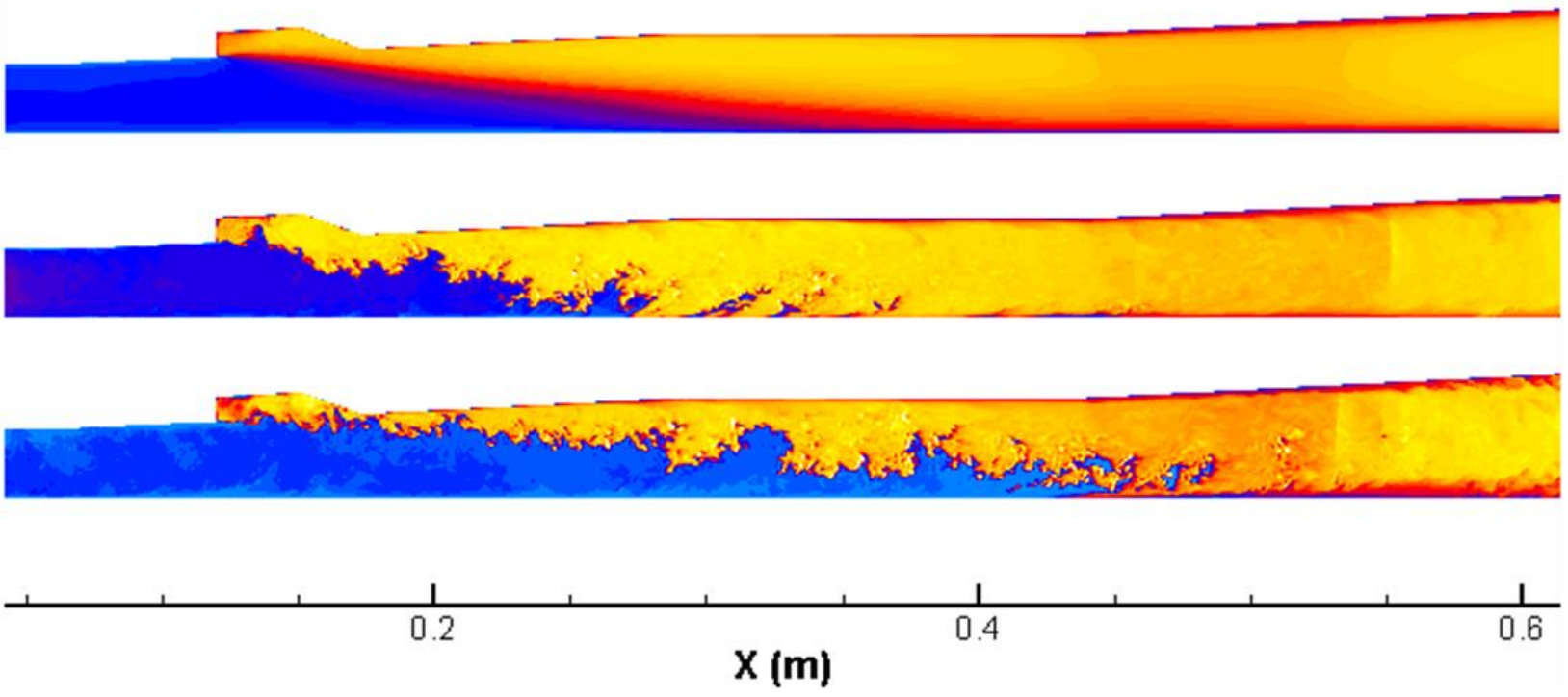

Figure 5: Temperature contours (top: average; middle: minimum heat release; bottom: maximum heat release)
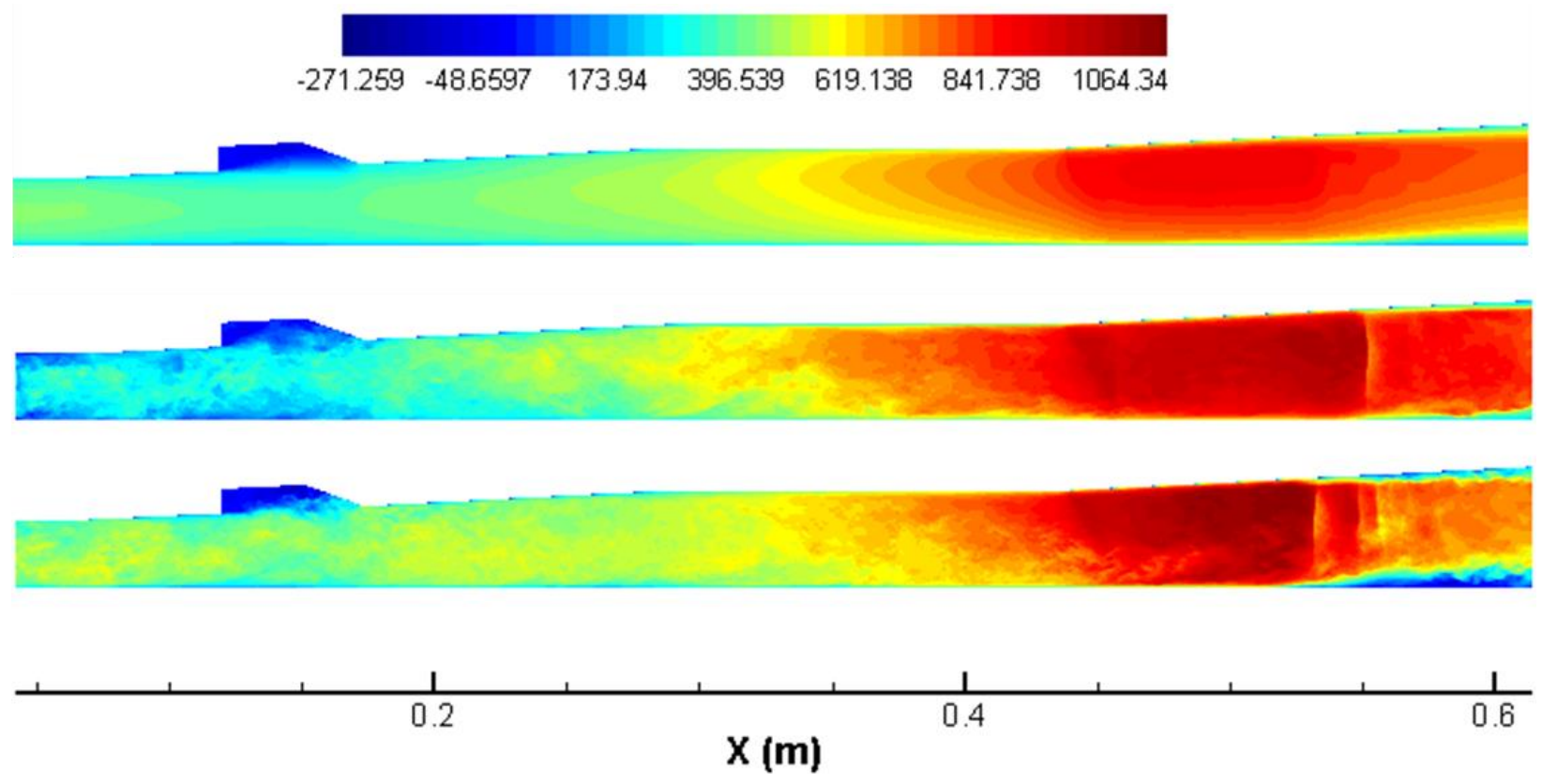

Figure 6: Axial velocity contours (top: average; middle: minimum heat release; bottom: maximum heat release) 


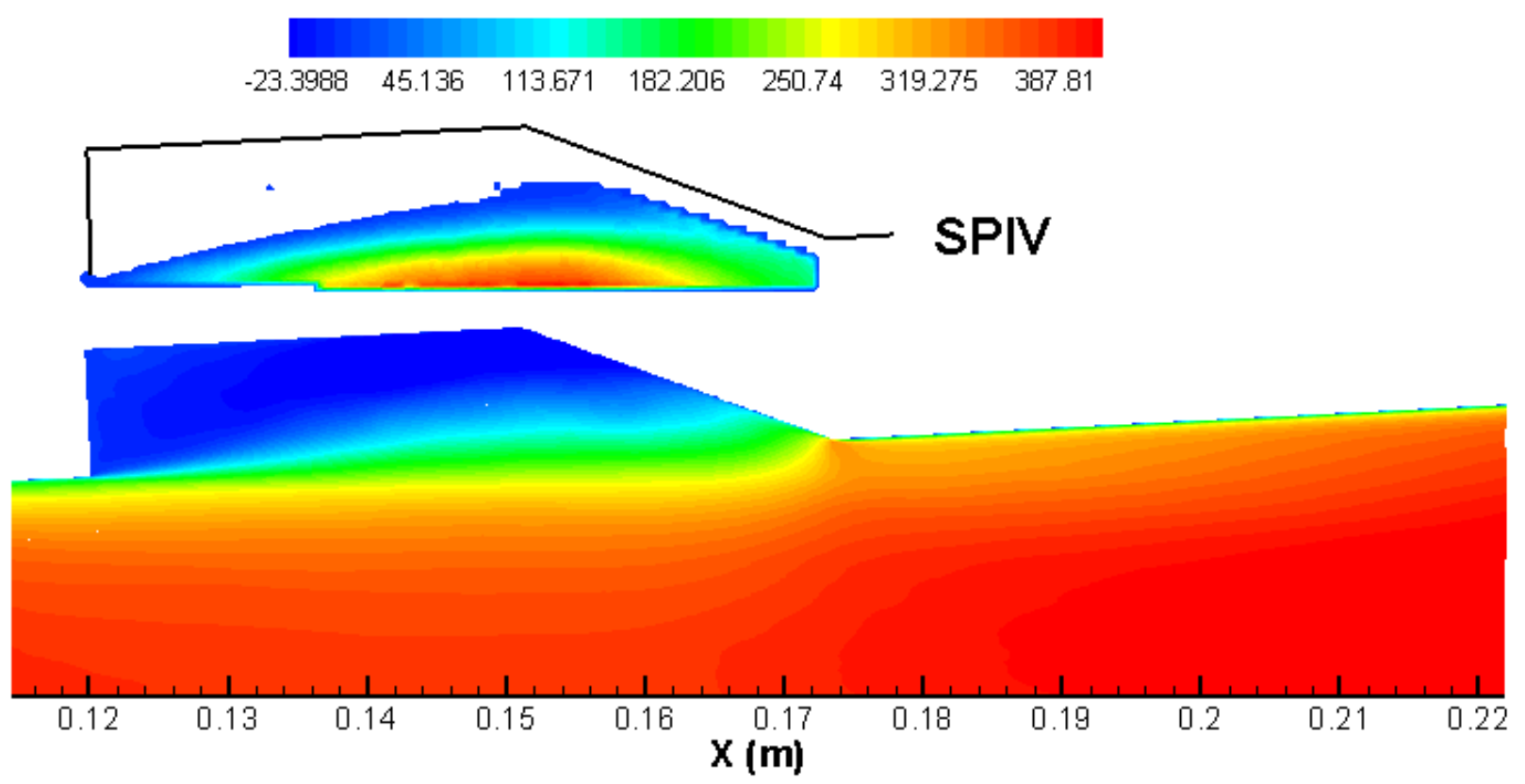

Figure 7: Comparison of centerline axial velocity with PIV data

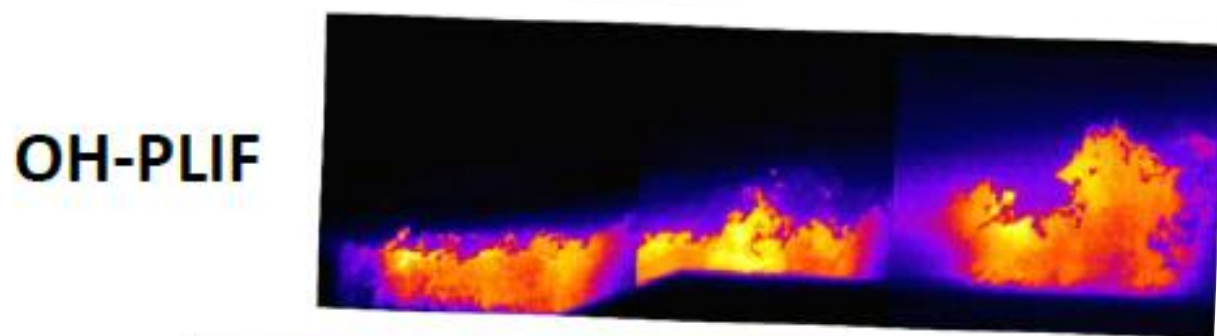

$2.00 \mathrm{E}-04 \quad 1.51 \mathrm{E}-03 \quad 2.82 \mathrm{E}-03 \quad 4.13 \mathrm{E}-03$
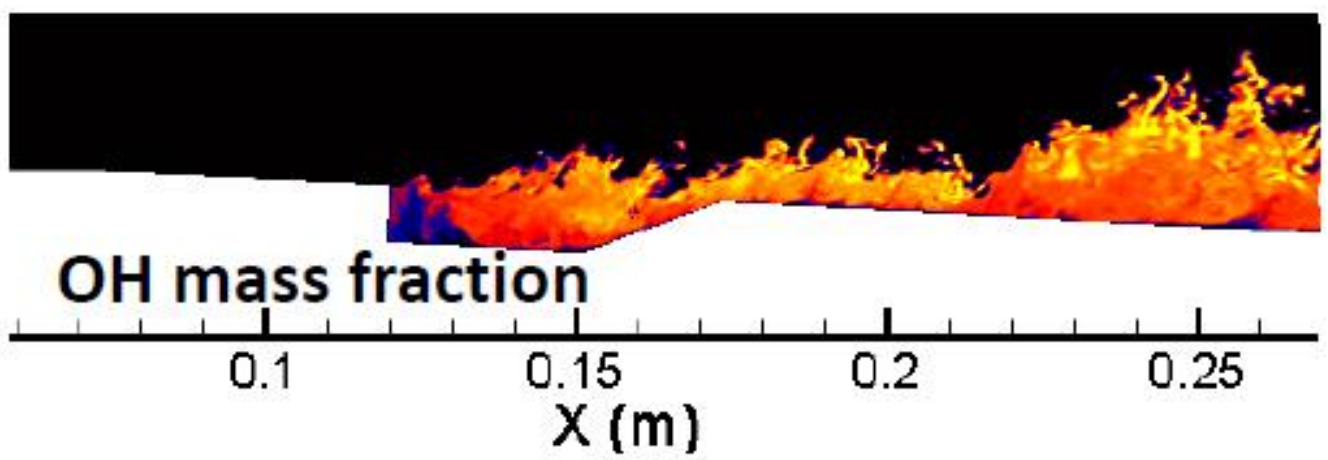

Figure 8: Comparison of OH-PLIF with $\mathrm{OH}$ mass fraction near cavity 

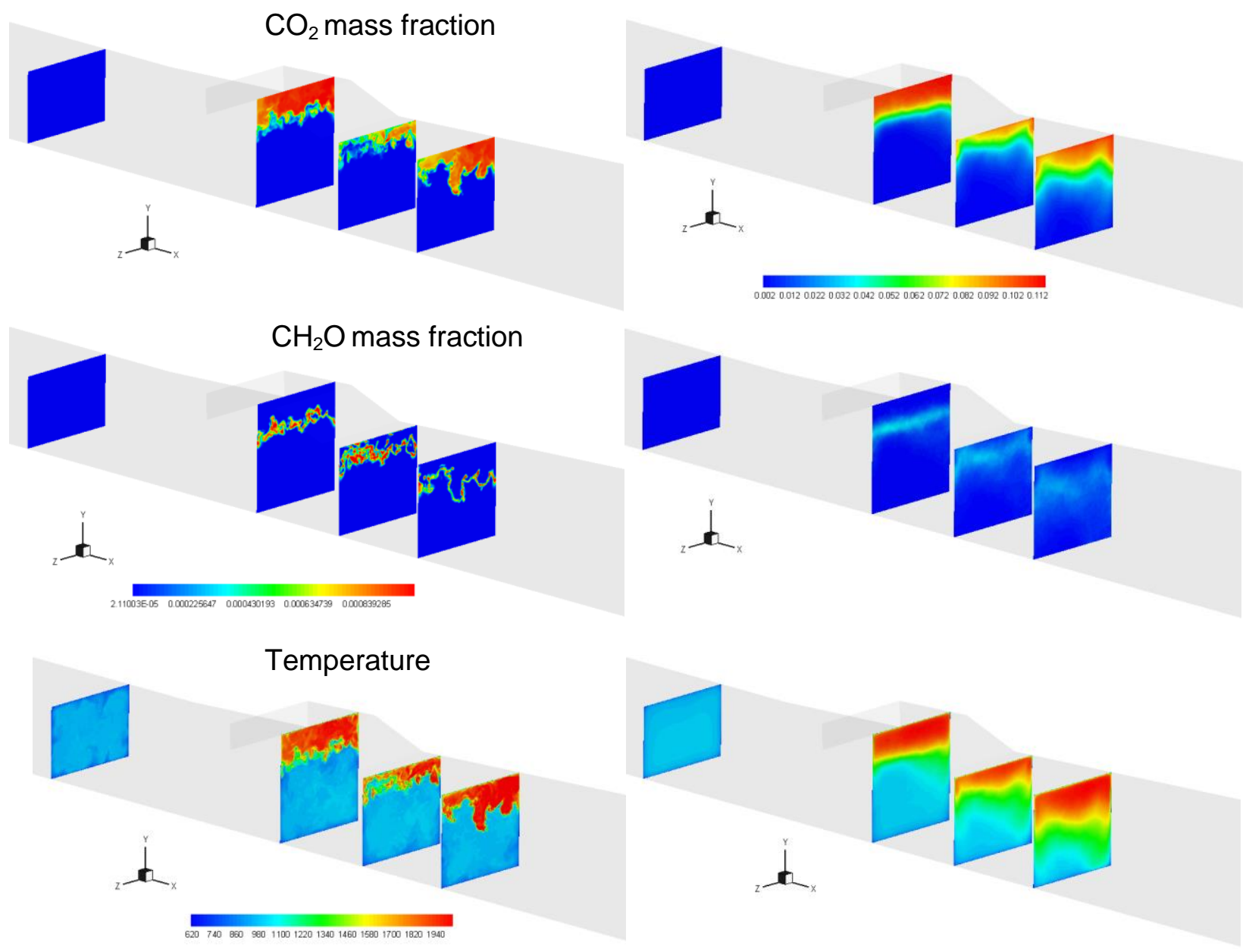

Figure 9: Three-dimensional flame structure (left: instantaneous; right: average) 


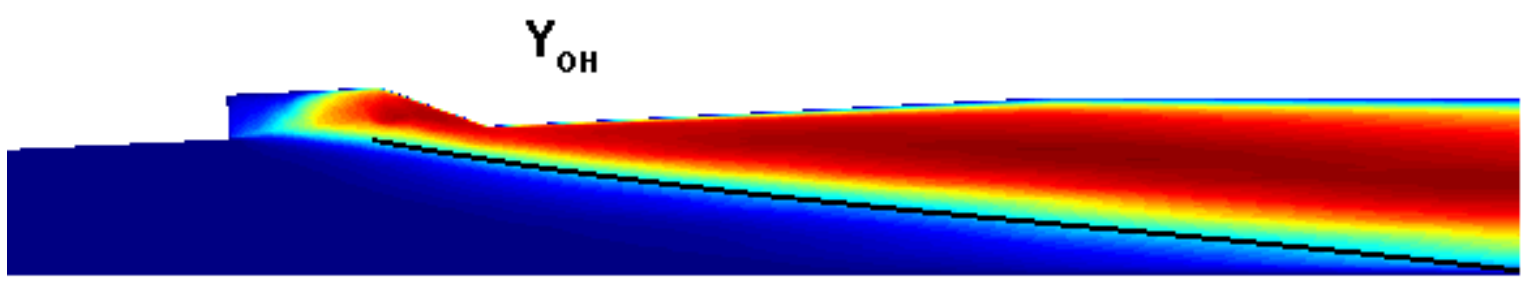

Temperature

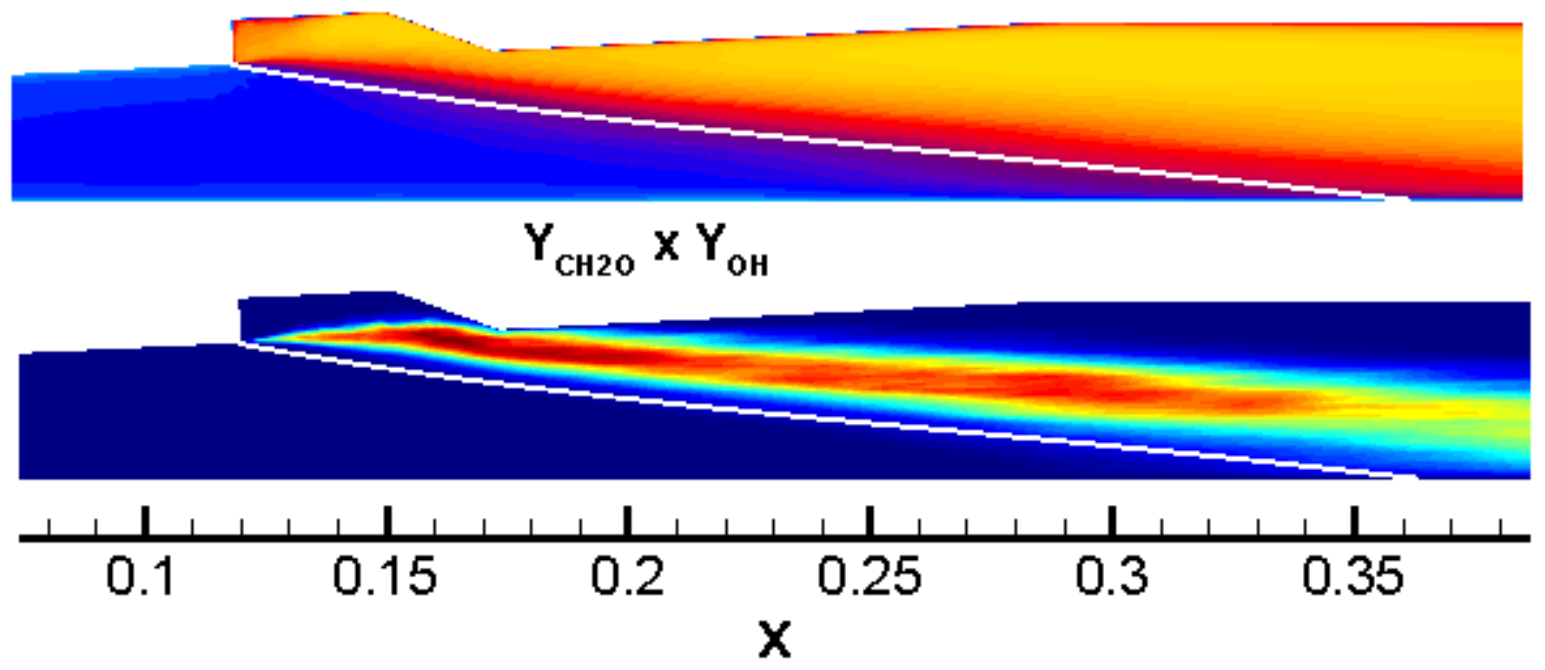

Figure 10: Flame angle predictions (white lines) versus time-averaged data

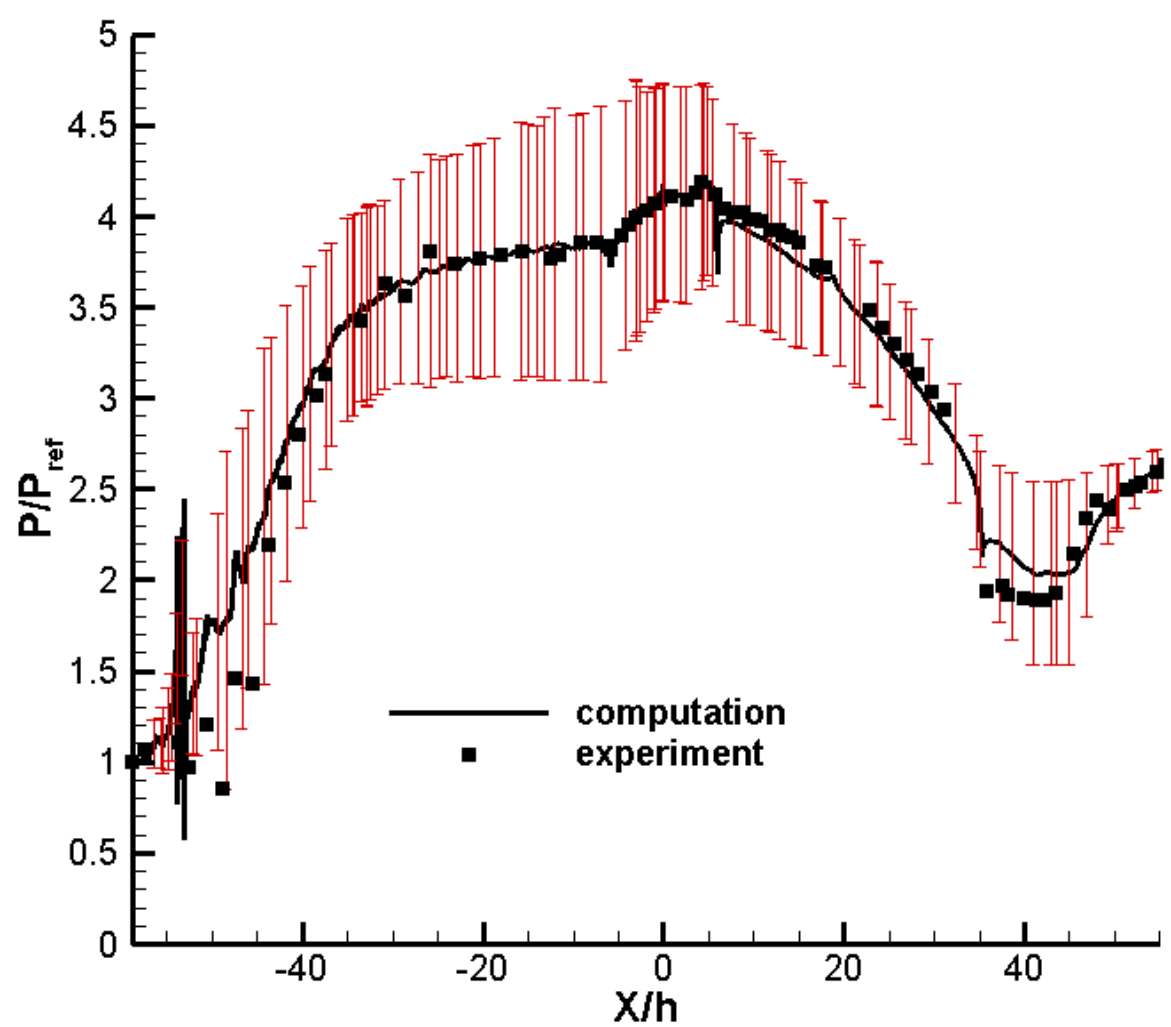

Figure 11: Wall pressure distributions with one standard deviation in pressure fluctuations shown as 'error bars' 


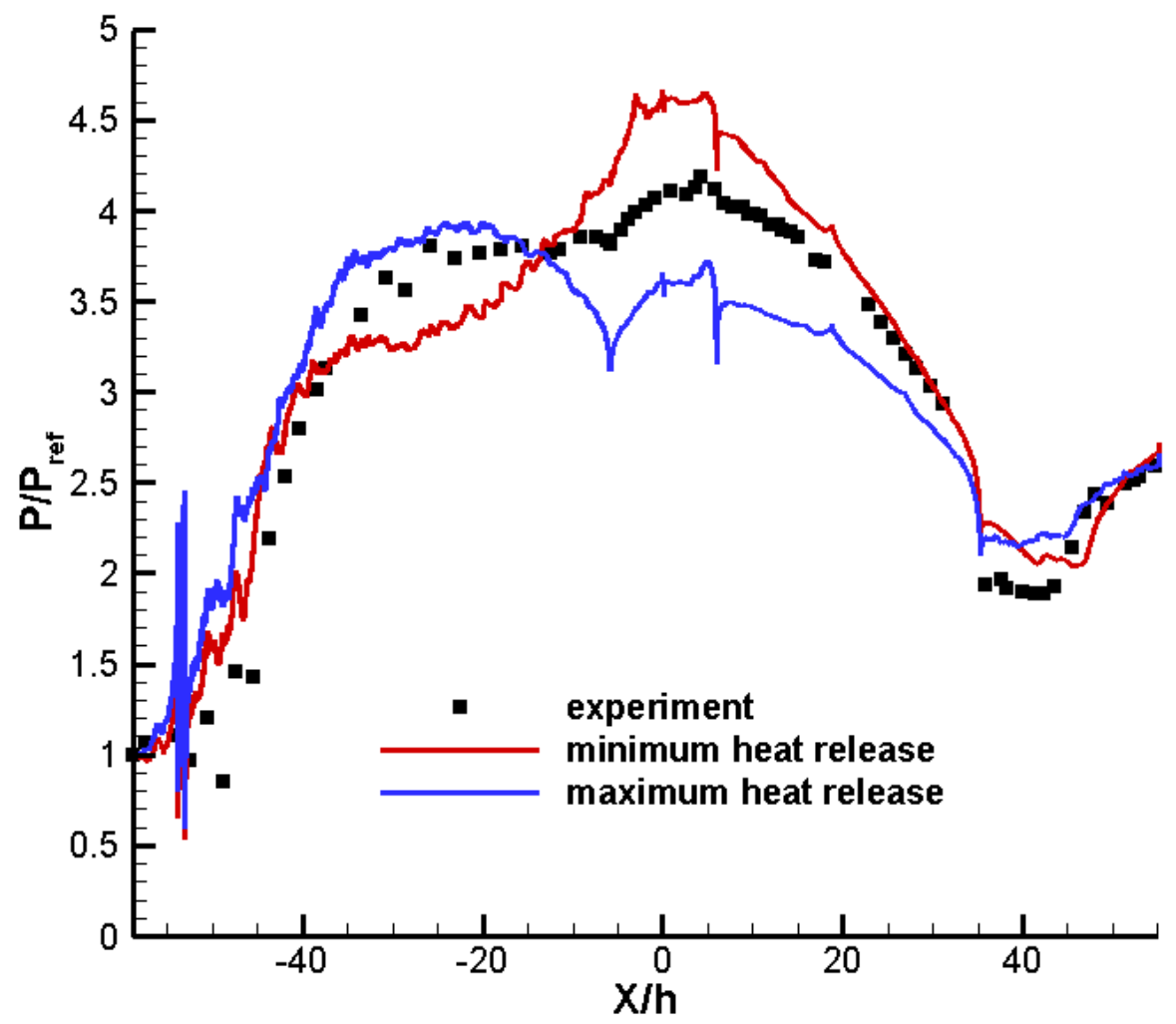

Figure 12: Wall pressure distributions conditionally averaged based on heat release

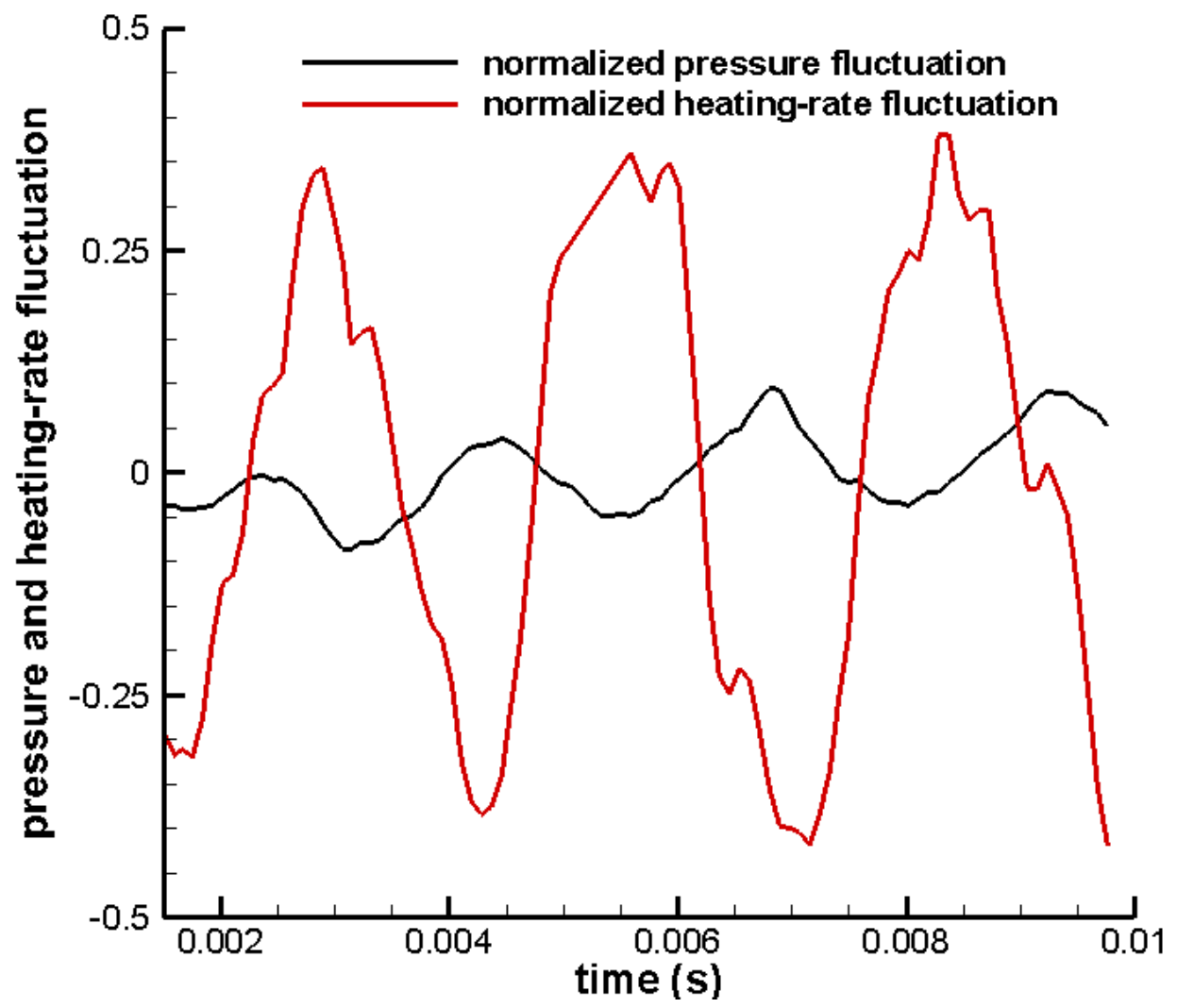

Figure 13: Average pressure fluctuation and heat-release fluctuation levels versus time 


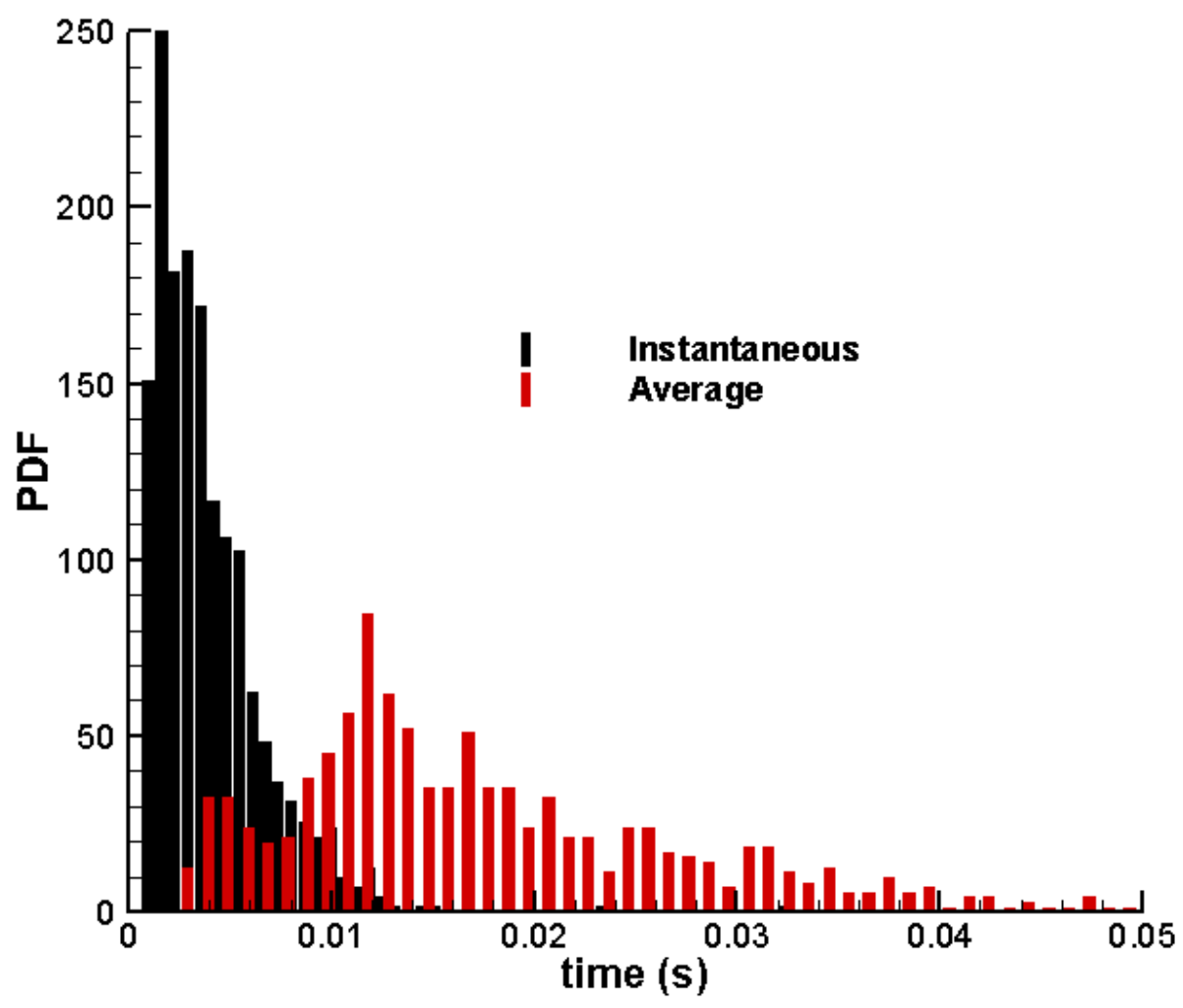

Figure 14: Residence time distributions within cavity (instantaneous vs. time-average)

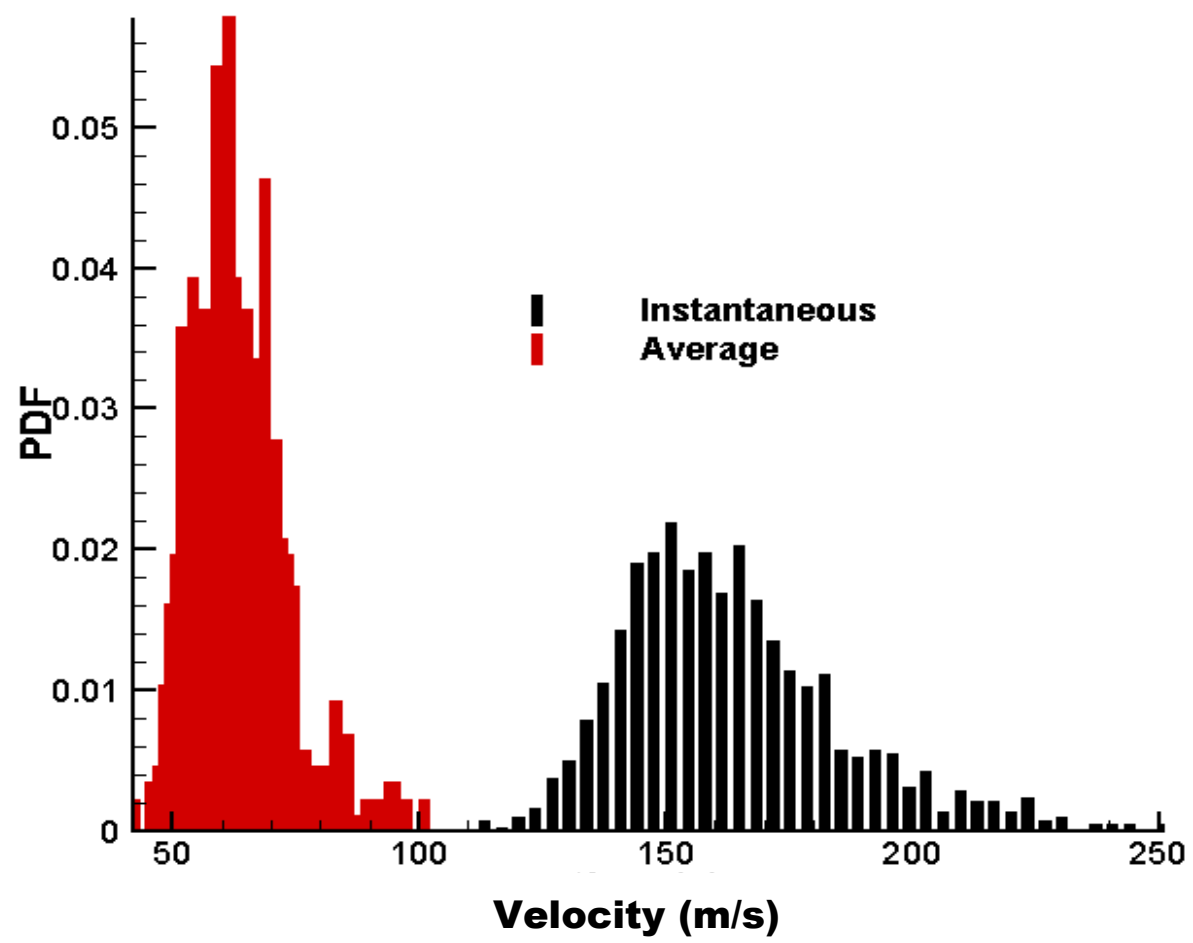

Figure 15: Velocity distributions within cavity (instantaneous vs. timeaverage) 